\title{
Mechanism of Dislocation Channel-Induced Irradiation Assisted Stress Corrosion Crack Initiation in Austenitic Stainless Steel
}

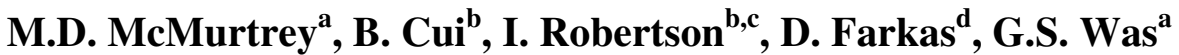 \\ ${ }^{a}$ Department of Nuclear Engineering and Radiological Sciences, University of Michigan, Ann Arbor, MI 48109, United States \\ ${ }^{b}$ Department of Materials Science and Engineering, University of Illinois, Urbana, IL 61801 ,United States \\ ${ }^{c}$ Department of Materials Science and Engineering, University of Wisconsin-Madison, WI 53706, United States \\ ${ }^{d}$ Department of Materials Science and Engineering, Virginia Tech, Blacksburg, VA 24061, United States
}

Corresponding Author:

Gary S. Was

2355 Bonisteel Blvd

University of Michigan

Ann Arbor, MI 48109

$734763-4675$

Fax $734736-4540$

gsw@umich.edu 


\title{
Mechanism of Dislocation Channel-Induced Irradiation Assisted Stress Corrosion Crack \\ Initiation in Austenitic Stainless Steel
}

\author{
M.D. McMurtrey ${ }^{a}$, B. Cuib ${ }^{\mathrm{b}}$, I. Robertson ${ }^{\mathrm{b}, \mathrm{c}}$, D. Farkas ${ }^{\mathrm{d}}$, G.S. Was ${ }^{\mathrm{a}}$ \\ ${ }^{a}$ Department of Nuclear Engineering and Radiological Sciences, University of Michigan, Ann Arbor, MI 48109, United States \\ ${ }^{b}$ Department of Materials Science and Engineering, University of Illinois, Urbana, IL 61801 , United States \\ ${ }^{c}$ Department of Materials Science and Engineering, University of Wisconsin-Madison, WI 53706 , United States \\ ${ }^{d}$ Department of Materials Science and Engineering, Virginia Tech, Blacksburg, VA 24061, United States \\ *Corresponding author at 1906 Cooley Building, 2355 Bonisteel Blvd, Ann Arbor, MI 48106, United States. Tel.: 1734936 \\ 0266; Fax: 1734763 4540; email: mdmcm@umich.edu
}

\begin{abstract}
The mechanism by which dislocation channeling induces irradiation assisted stress corrosion cracking was determined using Fe-13Cr15Ni austenitic stainless steel irradiated with protons to a dose of 5 dpa and strained at high temperature in both argon and simulated boiling water reactor normal water chemistry environments. Straining induced dislocation channels that were characterized by digital image correlation and confocal microscopy. Dislocation channels were found to be either continuous across the boundary, discontinuous, or discontinuous with slip in the boundary. Discontinuous channels were found to contain the least amount of strain but have the highest propensity for initiating cracks. Discontinuous dislocation channel - grain boundary intersections were shown to have the highest local stress. TEM in-situ straining of irradiated steels and atomistic simulation of dislocation-grain boundary interaction provided supporting evidence that channels that were unable to transfer strain underwent cracking. The inability of channels to relieve stress, by either slip in the adjacent grain or in the grain boundary, resulted in high local stresses and increased susceptibility to stress corrosion cracking initiation.
\end{abstract}

\section{Introduction}

Austenitic stainless steel is used in light water reactors for various core components because of its high resistance to corrosion. However, under irradiation it is susceptible to 
intergranular stress corrosion cracking (IGSCC), termed irradiation assisted stress corrosion cracking (IASCC) [1]-[3]. The exact mechanism behind IASCC is not well understood. Irradiation causes a number of changes to the microstructure of the steel, including radiation induced segregation (RIS), radiation hardening, and a change in the deformation mechanism from relatively homogeneous slip to heterogeneous slip, with deformation confined to coarsely spaced bands referred to as dislocation channels. The complexity of the irradiated microstructure makes it difficult to separate the individual effects on IASCC.

Early research focused on chromium depletion due to RIS at the grain boundary as the key factor responsible for increased cracking susceptibility, similar to the increased cracking susceptibility in sensitized steel. More recent data, however, has showed that, while chromium depletion plays a role in IASCC, it is not likely the dominant factor [4], [5]. In the work by Busby et al. [4], irradiation effects were found to recover at different rates during annealing, and in particular, it was observed that cracking susceptibility recovers much more rapidly than RIS. Cracking correlates with yield strength, but the correlation lacks a physical basis. More recent work has identified dislocation channeling as a potential factor controlling IASCC [1], [2], [6][9] that is linked to the yield strength of the material. Dislocation channeling is a phenomenon that occurs as applied stresses reach the critical resolved shear stress and dislocations are pushed through the irradiation damaged microstructure. As the dislocations move along the slip plane, they clear some of the defect clusters formed by irradiation. Subsequent dislocations are more likely to follow the same path due to the lower density of defects, causing deformation to be highly localized and heterogeneous. The critical resolved shear stress is higher in irradiated metals[10], causing an increase in yield strength prior to relief through the creation and slip of dislocations. 
Dislocation channels are characterized by their width $(\sim 0.1 \mu \mathrm{m})$, spacing (generally 1-3 $\mu \mathrm{m})$, and the amount of shear strain in the channel[11], [12]. The amount of shear strain in the dislocation channels is difficult to analyze experimentally. Strain in the channel has been estimated by measuring the step height caused by the channel on the specimen surface [6], as well as the offset the channel caused when it intersected a grain boundary [13]. Using these methods of measurement, strain within dislocation channels was found to be around two orders of magnitude higher than the bulk applied strain.

The high amount of strain in the dislocation channels is accompanied by elevated levels of stress as predicted by computer modeling. Evrard and Sauzay [14], [15] used a finite element model to simulate the intersection between channels and grain boundaries. Dislocation channels were modeled as soft regions (low critical resolved shear stress) in a hard grain (high critical resolved shear stress). Areas of high stress were found at the intersection of the channel with the grain boundary. Atomistic modeling has also shown high levels of stress due to dislocation impingement on grain boundaries [16], [17].

The degree of localized deformation in the form of discontinuous channels correlates strongly with cracking [17], [18]. Was et al. [19] discussed possible mechanisms relating localized deformation and IASCC. Three forms of dislocation channel - grain boundary (DCGB) interactions were considered: Continuous slip across the grain boundary, discontinuous slip with dislocation absorption into the grain boundary (disc. w/ GB slip) resulting in grain boundary sliding, and discontinuous slip resulting in a dislocation pileup where slip is not accommodated in any form. Of these three, the latter two were considered the likely locations for crack initiation due high strain in the case of grain boundary sliding, and high stress in the case of the dislocation pileup. 
West and Was [20] identified a connection between IASCC susceptibility with stress at the grain boundary by using a Schmid-Modified Grain Boundary Stress (SMGBS) model to correlate grain boundary stress with IASCC. The SMGBS model used not only the orientation of the boundary plane with respect to the tensile axis, but also factored in the propensity of the grain for deformation, which was determined by the Schmid factor. Grains with low Schmid factors were determined to have a low propensity to deform, and this resulted in higher stress at the grain boundary, as well as a high propensity for cracking. DC-GB intersections where slip is not transmitted are also likely to cause localized areas of high stress, and are considered likely candidates to induce cracking, as described by Was et al. [19]. In this case, the dislocations are not able to be accommodated through slip transmission before the critical stress needed to induce cracking is reached.

Recently, digital image correlation (DIC) has been used to confirm that when a channel terminates at a grain boundary (discontinuous), two possible interactions may result [16]; the slip may be transmitted into the grain boundary, inducing grain boundary slip, or the slip may terminate at the grain boundary, resulting in unaccommodated slip. This work seeks to differentiate the roles of stress and grain boundary strain in the IASCC crack initiation mechanism.

\section{Experimental}

A controlled purity austenitic Fe-13Cr-15Ni alloy (Table 1) was used in this study. Electric discharge machining (EDM) was used to cut a tensile bar with a $21 \mathrm{~mm}$ gage length and a $2 \mathrm{~mm} \times 1.5 \mathrm{~mm}$ cross section. The EDM damage was removed with a mechanical polish, followed by an electropolish at $30 \mathrm{~V}$ in a solution of $10 \%$ perchloric acid and $90 \%$ methanol at - 
$40{ }^{\circ} \mathrm{C}$ for 90 seconds in order to remove all residual mechanical damage from the mechanical polish.

Table 1. Composition (wt\%) of Fe-13Cr15Ni austenitic steel used in this study.

\begin{tabular}{|l|l|l|l|l|l|l|l|}
\hline $\begin{array}{l}\text { Material } \\
\text { designation }\end{array}$ & $\mathrm{Fe}$ & $\mathrm{Cr}$ & $\mathrm{Ni}$ & $\mathrm{Mn}$ & $\mathrm{Si}$ & $\mathrm{P}$ & $\mathrm{C}$ \\
\hline \hline 13Cr15Ni & Bal. & 13.41 & 15.04 & 1.03 & 0.1 & $<0.01$ & 0.016 \\
\hline
\end{tabular}

After polishing, the sample was irradiated using $3 \mathrm{MeV}$ protons to $5 \mathrm{dpa}$ and at a temperature of $360^{\circ} \mathrm{C}$ at the Michigan Ion Beam Laboratory. The temperature was monitored by a two-dimensional thermal imager (IRCON® Stinger thermal imaging system) that tracked surface temperatures of the sample at high spatial resolution throughout the irradiation. The temperature was controlled using a combination of an electric heater inserted into the stage, and air flow through the stage. The sample temperature was maintained to within $9^{\circ} \mathrm{C}$ of the set temperature $\left(360^{\circ} \mathrm{C}\right)$.

The depth of the proton penetration into the sample was about $40 \mu \mathrm{m}$. The damage rate profile is shown in Figure 1, as determined using the full cascade model in SRIM ${ }^{\mathrm{TM}}$. The damage rate, as well as the total damage, is typically determined in the flat region prior to the peak. In this work, the damage rate was calculated to be $\sim 9 \times 10^{-6} \mathrm{dpa} / \mathrm{s}$ at a depth of $\sim 24 \mu \mathrm{m}$ and represented an average damage rate value in the flat region. It should be noted that recent results have shown that the full cascade method overestimates the damage by about a factor of 2 [21]. 


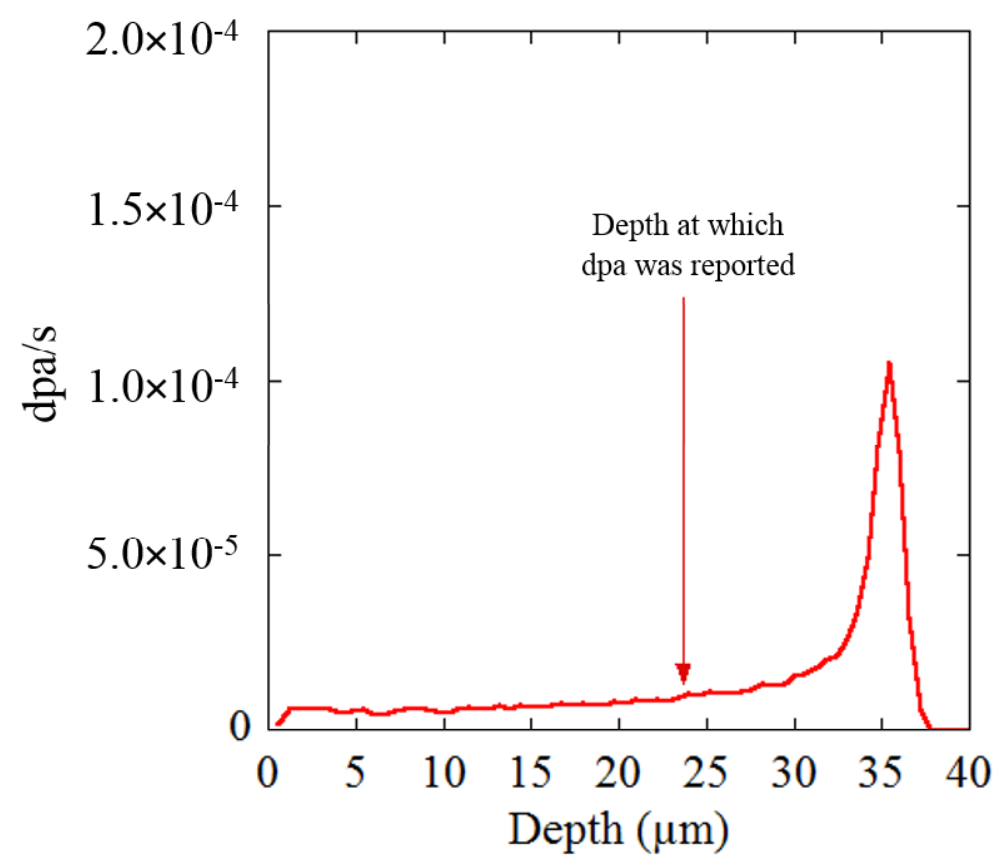

Figure 1. Damage rate profile for Fe-13Cr15Ni irradiated with $3 \mathrm{MeV}$ protons. The damage rate at a depth of $24 \mu \mathrm{m}$ was used to determine final dpa of the experimental sample.

In-plane displacements of strained samples were determined using DIC. To perform DIC, a gold speckle pattern was deposited on the tensile bar surface using $40 \mathrm{~nm}$ gold nanoparticles. The nano-particles were created by combining $1 \mathrm{~mL}$ of a solution consisting of 99 wt $\%$ water and $1 \mathrm{wt} \% \mathrm{Na}_{3}$-citrate to $100 \mathrm{~mL}$ of $0.01 \mathrm{wt} \% \mathrm{HAuCl}_{4}$ in distilled water which had been heated to a boil [22]. The tensile specimen was coated with (3-aminopropyl) trimethoxysilane and the gold nano-particles were deposited on the surface creating a speckle pattern, as shown in Figure 2. This deposition technique was originally developed for surface enhanced Raman spectrometry [23], but later used by Kammers [24] for DIC. 


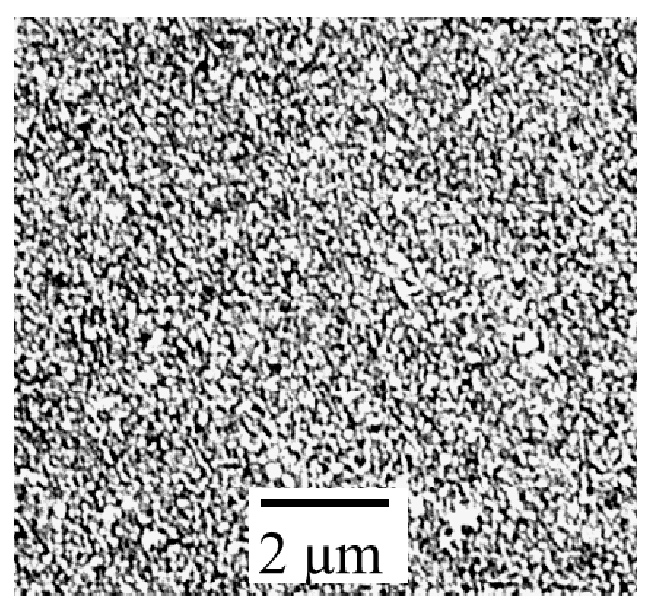

Figure 2. Gold (white) speckle pattern on Fe-13Cr15Ni steel (black).

The tensile sample was imaged in a JEOL JSM-6480 SEM both before and after straining, so that the two images could be correlated and displacement measured. As there is some distortion in the SEM imaging process, an Ultrasharp TGX01 AFM calibration grid (3 $\mu \mathrm{m}$ grid spacing) was imaged alongside the tensile bar at the same working distance. Distortion in the grid was corrected using Matlab ${ }^{\circledR}$ and the same image correction was applied to the images of the tensile bar surface.

The tensile bar was strained in two increments; to $1.5 \%$ plastic strain, followed by an additional $1 \%$ plastic strain increment for a total strain of $2.5 \%$ in high temperature $\left(288^{\circ} \mathrm{C}\right)$ argon at a strain rate of $\sim 3 \times 10^{-7} \mathrm{~s}^{-1}$. Slow strain rate testing was used to provide good control over the level of strain induced into the samples. DIC was performed after each strain increment, with the primary focus on the $2.5 \%$ straining step where a larger number of measurements were taken. Gold particles were removed by lightly cleaning with a polishing pad wetted with distilled water after the second strain increment so that the gold particles would not affect the corrosion of steel when placed in the high temperature BWR water environment. DIC does not provide any topographical information (out-of-plane displacement), so an Olympus OLS4000 
LEXT Confocal microscope was used to take the topographical measurements of the sample surface after the $2.5 \%$ strain in argon. Changes in displacement were measured across dislocation channels and grain boundaries, and the magnitude of all three vectors was calculated to determine the total displacement caused by the dislocation channel. Shear strain within the channel was calculated by assuming the dislocation channels were $100 \mathrm{~nm}$ wide [11], and dividing the total displacement by the width of the channel.

Residual stress measurements were made at various DC-GB intersections after straining to $2.5 \%$ using BLG Production's CrossCourt 3 electron backscatter diffraction (EBSD) analysis software. This technique relies on the cross correlation of areas of interest in the EBSD patterns between the measurement pattern and a reference pattern, as explained by Wilkinson et al. [25]. Reference patterns were taken from areas well removed from the GB - DC intersections, where stress is likely to be close to zero. The small shifts in the EBSD pattern are correlated to distortions in the crystal lattice caused by elastic strain. From these shifts, the elastic strain tensor is determined, and the elastic stress tensor calculated using Hooke's law. EBSD patterns were collected at points $100 \mathrm{~nm}$ apart, with the electron beam maintained on each measurement point for 3 seconds to collect high quality patterns. Twenty regions of interest were selected on each EBSD pattern, which were correlated with the reference pattern to measured elastic strain.

After analysis of the samples strained in argon, additional straining to $4.5 \%$ and then $7.2 \%$ was conducted in simulated boiling water reactor normal water chemistry (BWR NWC) conditions ( $288^{\circ}$ water with a conductivity maintained at $0.2 \mu \mathrm{S} / \mathrm{cm}$ and dissolved oxygen at $\sim 2$ ppm). These slow strain rate tests allow for cracking to be accelerated over what would occur normally in the light water reactor components under a high load. The slow strain rate tests also allow of good control so that straining could be stopped while cracks were small. Straining was 
performed incrementally so that crack initiation sites could be located before the cracks propagated to larger sizes and obscured the initiation site. After straining in water, cracks were located and characterized based on prior DC-GB information determined after the argon straining steps.

The statistical significance of the cracking results was determined using a binomial distribution model from which the standard deviation $(\sigma)$ was used to determine the amount of error in the measurements. Standard deviations for binomial distributions are calculated as

$$
\sigma_{x}=\sqrt{x(1-p)}
$$

where $x$ is the number of cracks at the DC-GB type being studied and $p$ is the probability of the crack occurring at the DC-GB type in question, defined as

$$
p=\frac{x}{n}
$$

The value $n$ is the total number of DC-GB intersections of the type being studied. In terms of the fractional uncertainty of the probability of cracking,

$$
\frac{\sigma_{p}}{p}=\sqrt{\frac{1}{n} \frac{(1-p)}{p}} .
$$

This statistical analysis was used to calculate error in the measurements taken of cracking at each of the three types of DC-GB intersections.

\section{Results}

3.1 Characterization of DC-GB intersections following straining in an argon gas environment 
All measured DC-GB intersections were characterized as one of three possible types: Continuous, disc. w/ GB slip, or discontinuous. Continuous intersections are those where slip is transferred from one grain to the next and are identified by channels in adjacent grains that meet at the grain boundary. They may occur by direct transmission of the dislocation across the grain boundary or by the formation of a new dislocation source in the adjacent grain at the point where the incoming channel intersects the grain boundary. Disc. w/ GB slip are channels that terminate at the grain boundary but which give rise to measurable slip in the boundary. Discontinuous channels terminate at the grain boundary with no evidence of slip transmission into an adjacent grain or in the grain boundary.

Total (sum of in-plane and out-of-plane) displacement in the dislocation channels at the DC-GB intersection, shown in Figure 3 after straining to 2.5\%, was largest at continuous intersections, and smallest at discontinuous, which is in agreement with earlier work on $\mathrm{Fe}$ $13 \mathrm{Cr} 15 \mathrm{Ni}$ strained to $3.5 \%$ in an argon gas environment [16]. The average and maximum displacements of each DC-GB intersection type are given in Table 2, and clearly show that discontinuous channels exhibited far less displacement than channels that were classified as continuous or disc. w/ GB slip, both on average displacement and in the maximum. Grain boundary displacement measurements (GB in Figure 3) are also shown for cases of disc. w/ GB slip. On rare occasion, a continuous DC-GB intersection will also experience grain boundary slip. Two cases were observed in this work, of the 126 cases of continuous DC-GB intersections identified after the $2.5 \%$ strain was applied to the specimen. These two cases $(\sim 120$ and $30 \mathrm{~nm}$ displacement) were not included in the grain boundary displacement measurements of Figure 3. 


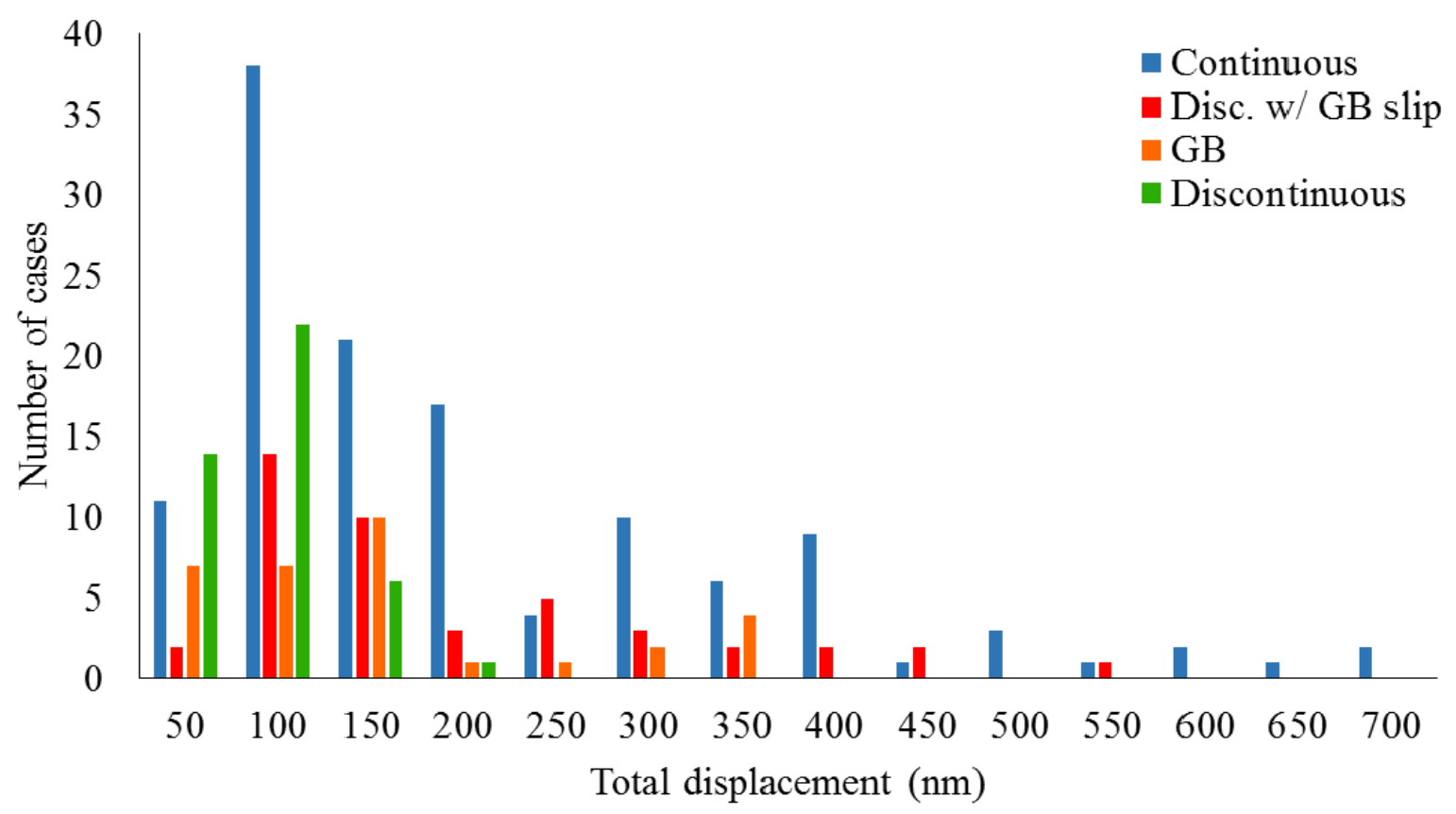

Figure 3. Total displacement in the grain boundary after $2.5 \%$ strain in argon by DC-GB intersection type (continuous, disc. w/ GB slip and discontinuous). Grain boundary displacement measurements from Disc w/ GB slip are also included and account for only the displacement due to a single dislocation channel.

Table 2. Average and maximum displacement in dislocation channels for each DC-GB intersection type (including both channel and grain boundary displacement measurements for disc. w/ GB slip). Measurements taken after $2.5 \%$ strain in an argon environment at $288^{\circ} \mathrm{C}$.

\begin{tabular}{|c|c|c|c|c|}
\hline & Continuous & $\begin{array}{c}\text { Disc. } \\
\text { channel }\end{array}$ & $\begin{array}{l}\text { / GB slip } \\
\text { boundary }\end{array}$ & Discontinuous \\
\hline Average displacement (nm) & 185 & 172 & 132 & 66 \\
\hline Maximum displacement (nm) & 660 & 541 & 320 & 174 \\
\hline
\end{tabular}

The grain boundary displacements shown in Figure 3 and Table 2 are the displacement measurements caused by a single dislocation channel. Multiple channels may intersect the 
boundary and contribute to the total amount of slip. Figure 4 shows an SEM image of multiple disc. w/ GB slip dislocation channels, each inducing grain boundary slip, as seen in the XY shear strain map on the right-hand side, causing the amount of slip in the boundary to increase towards the bottom of the image. In order to report grain boundary slip due to a single channel, displacement was measured along the grain boundary on both sides of a DC-GB intersection, and the difference in the two measurements was attributed to the boundary slip caused by the dislocation channel. Figure 5 shows the total displacement in the grain boundary, resulting from all dislocation channels intersecting the grain boundary, rather than the displacement in the boundary from a single channel, as in Figure 3. In terms of the effects of grain boundary slip on cracking, the results in Figure 5 are more relevant, as they represent the actual slip experienced by the boundary, rather than just the portion due to a single channel, as shown in Figure 3.

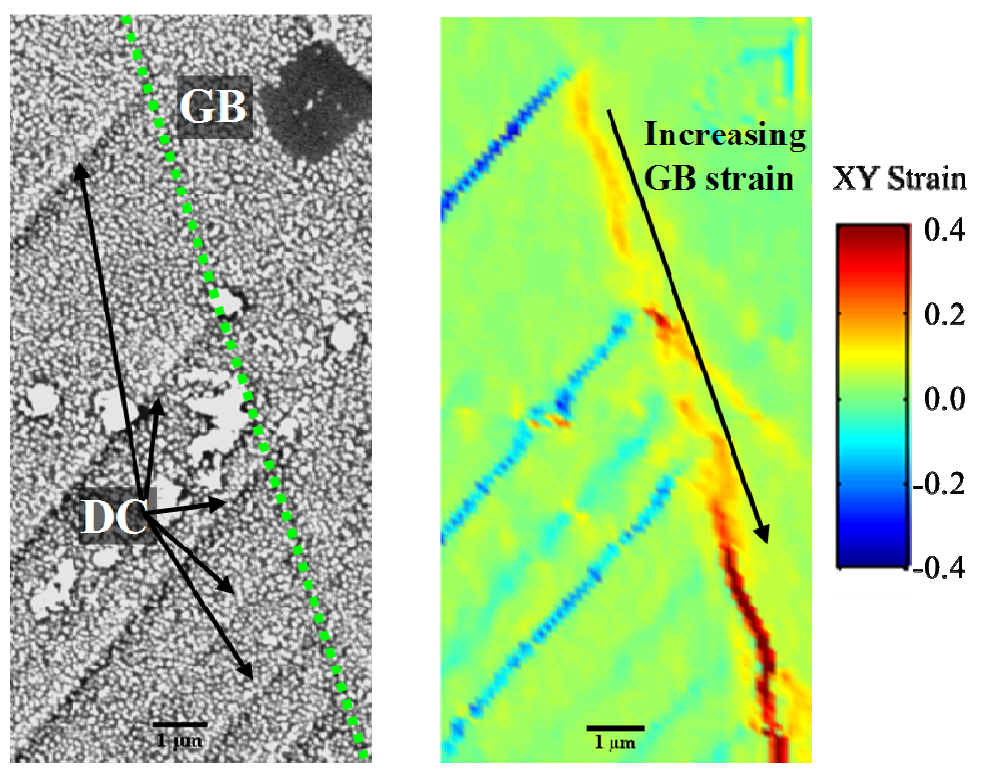

Figure 4. Example of Disc w/ GB slip intersection, where each dislocation channel contributes to additional slip in the boundary. The right-side image shows the XY shear strain map. 


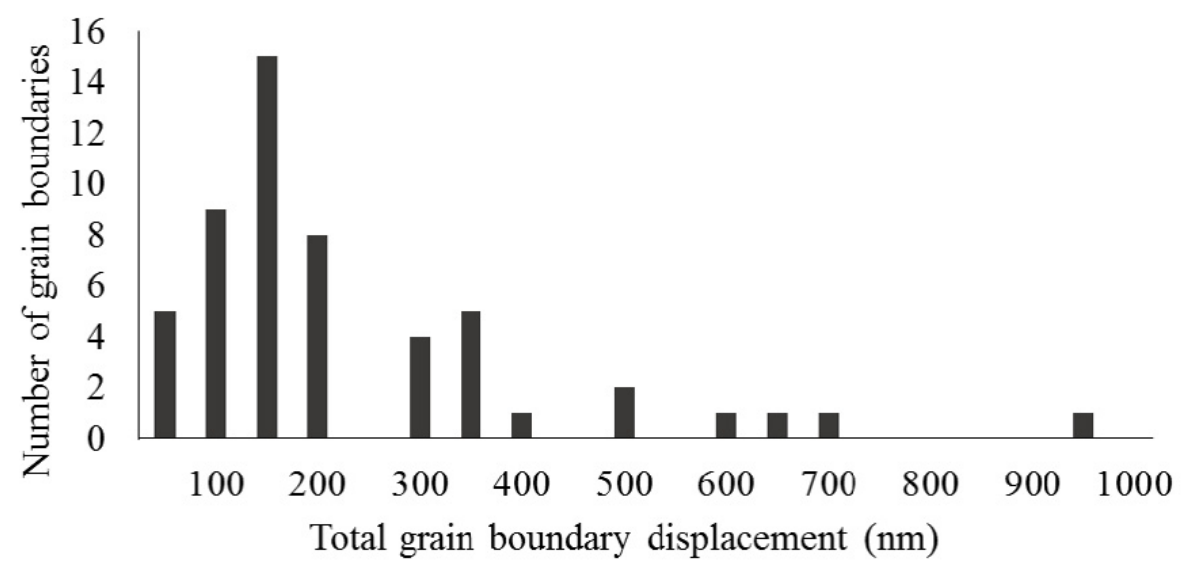

Figure 5. Total displacement in grain resulting from all DCs intersecting the grain boundary.

Straining in the argon environment was performed in two increments, $1.5 \%$ and $1 \%$ strain, to a total of $2.5 \%$. Figure 6 shows the in-plane slip distribution after the two strain increments. All channels were found to undergo additional slip when the overall sample strain was increased from $1.5 \%$ to $2.5 \%$. Of the 44 DC-GB intersections characterized, 33 were continuous, and the strain in the channels increased, on average, $144 \%$. Seven were D/GB and strain in the channels increased by $91 \%$ on average. Strain in the four discontinuous channels increased, on average, by $151 \%$. With additional strain, slip transmission from the DC-GB intersection occurs on occasion. Figures 7 shows one of two intersections that were found to change classifications, this one from discontinuous to disc. w/ GB slip (the other went from discontinuous to continuous). These were not included in the 44 slip measurements where average changes in slip were determined for each DC-GB intersection type. 


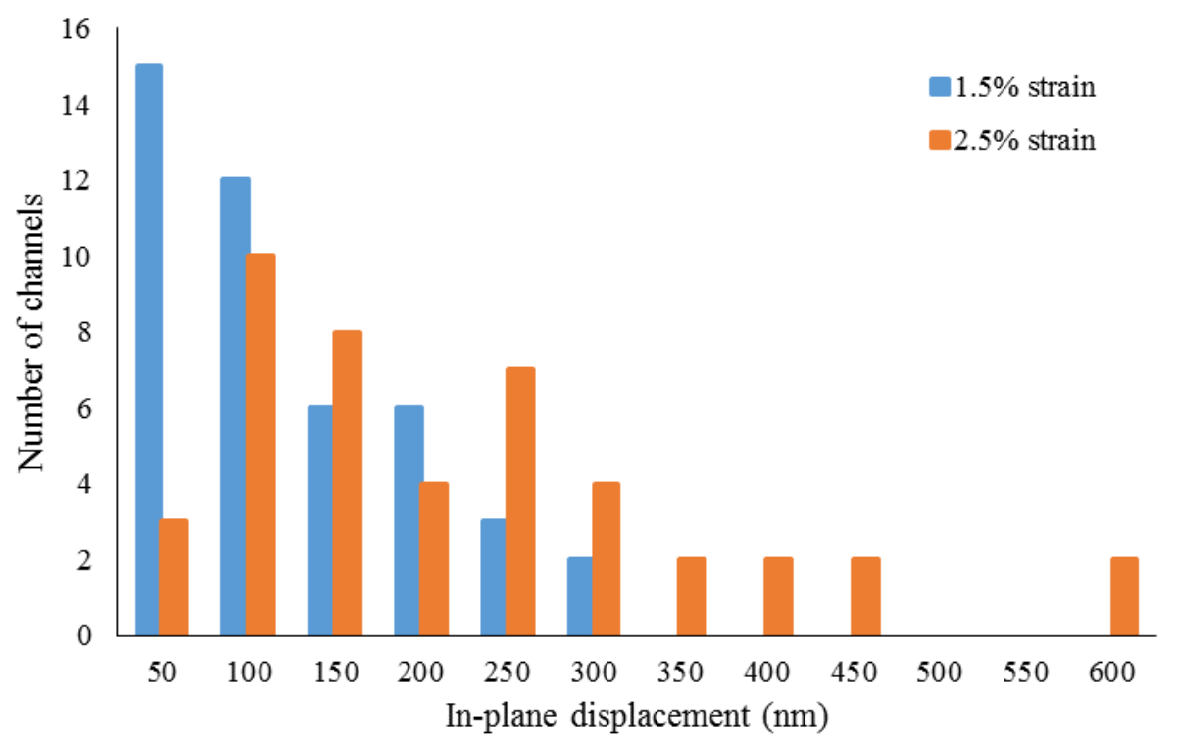

Figure 6. In-plane slip distribution of the same channels measured after $1.5 \%$ strain and $2.5 \%$ strain in argon.
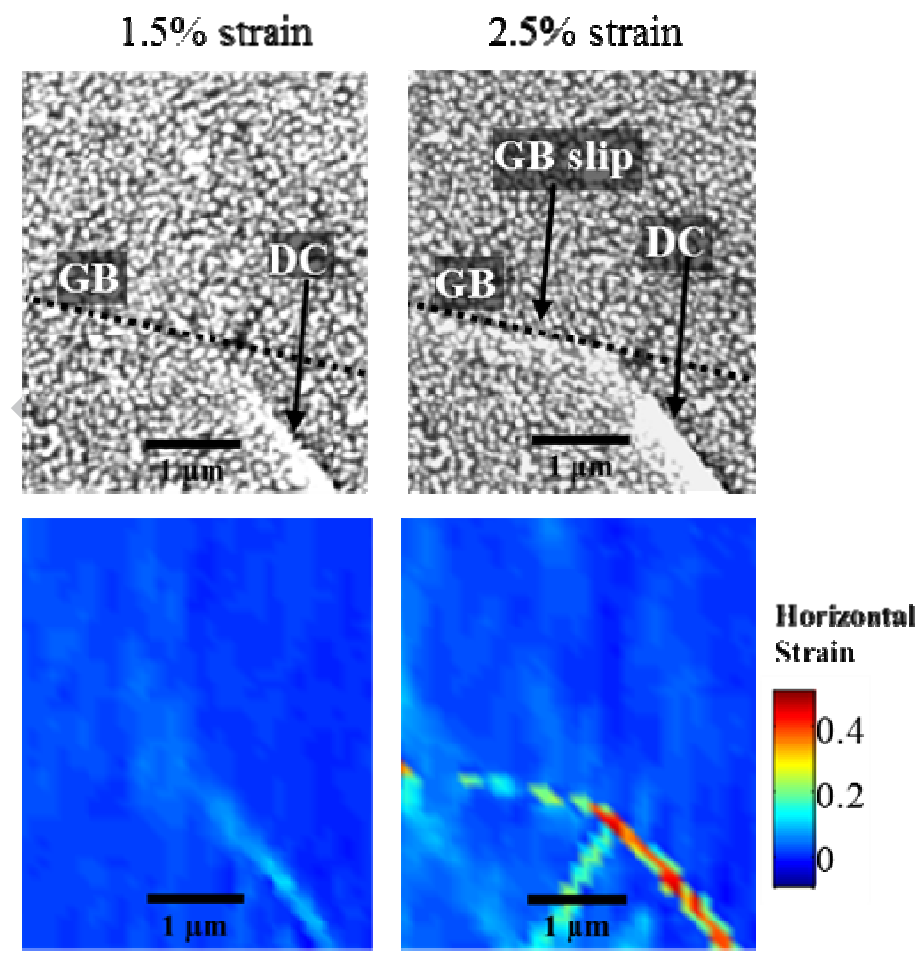
Figure 7. SEM image and horizontal (tensile axis) strain map of DC-GB intersection at $1.5 \%$ macroscopic strain (left) and 2.5\% macroscopic strain (right). At 2.5\%, the channel, which initially appeared to be discontinuous, initiated grain boundary slip, becoming disc. w/ GB slip.

High resolution EBSD measurements were taken at each of the DC-GB intersection types to determine the stress (based on elastic strain measurements) at the intersection. In total, 48 intersections were measured, 28 taken after the $2.5 \%$ strain and 20 from a second sample strained to $3.5 \%$ in argon [16]. Examples of each DC-GB type are shown in Figure 8. Here the SEM image is shown in the left column and an inverse pole figure EBSD map showing grain orientation is in the center. The column on the right shows the Von Mises stress maps created using CrossCourt 3, as described previously in the experimental section. White areas of the stress maps are locations where the EBSD pattern was not clear enough to perform a cross correlation. The data from the most complete maps (with the fewest missing pixels) were collected in graphs shown in Figure 9, where the average stress is given as a function of distance (average of the measurements taken in a circle of a given radius from the DC-GB intersection). The different colors on the graph represent different DC-GB intersections. A general rise is noted as $r$ approaches zero, which is the location of DC-GB intersection. This rise is more noticeable in the graph showing stress near the intersection with a discontinuous channel. 

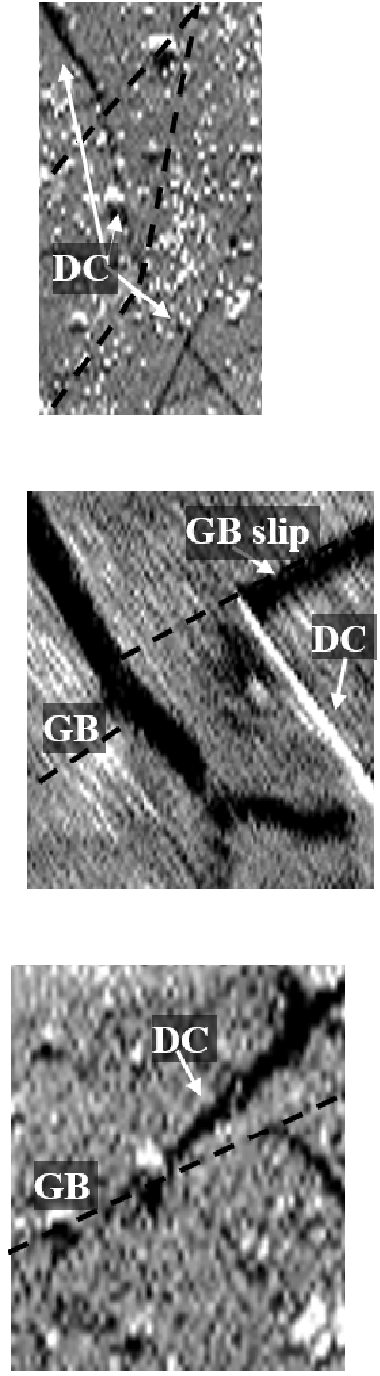

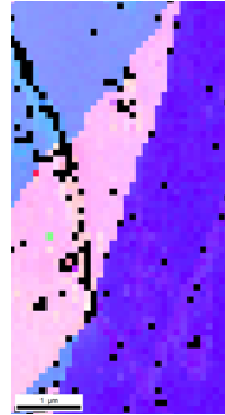

(a)
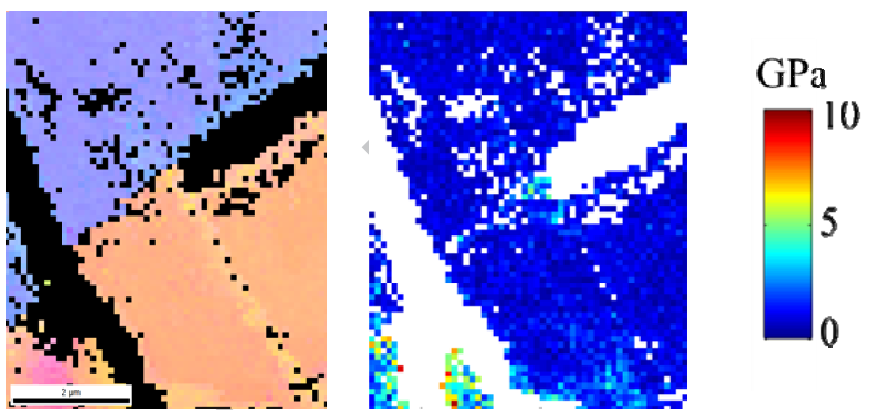

(b)
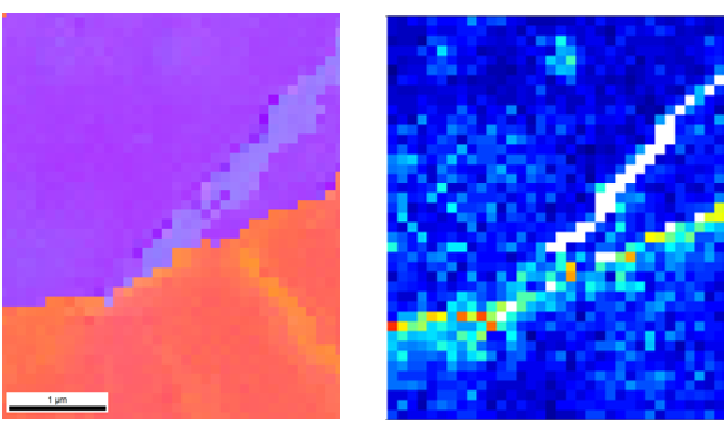

(c)

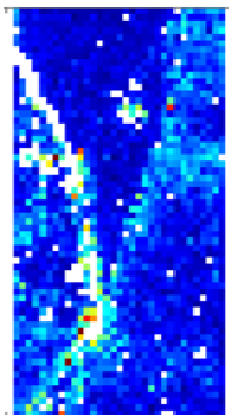


where data could not be collected. Shown in this figure are examples of (a) continuous, (b) disc. w/ GB slip, and (c) discontinuous DC-GB intersections.

Continuous

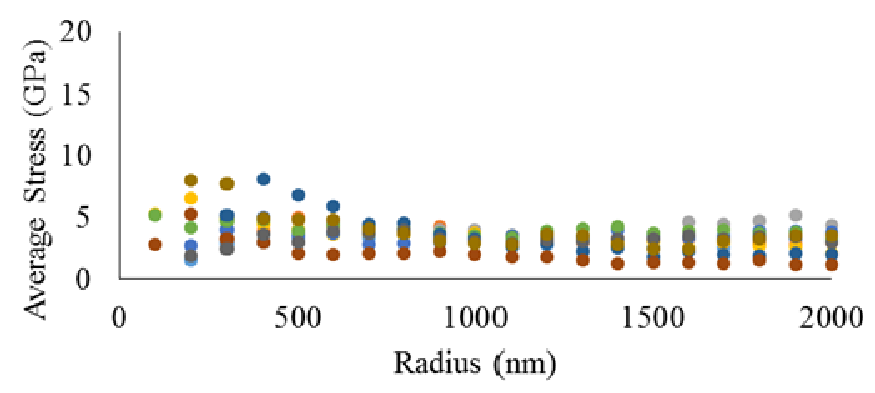

Disc. w/ GB slip
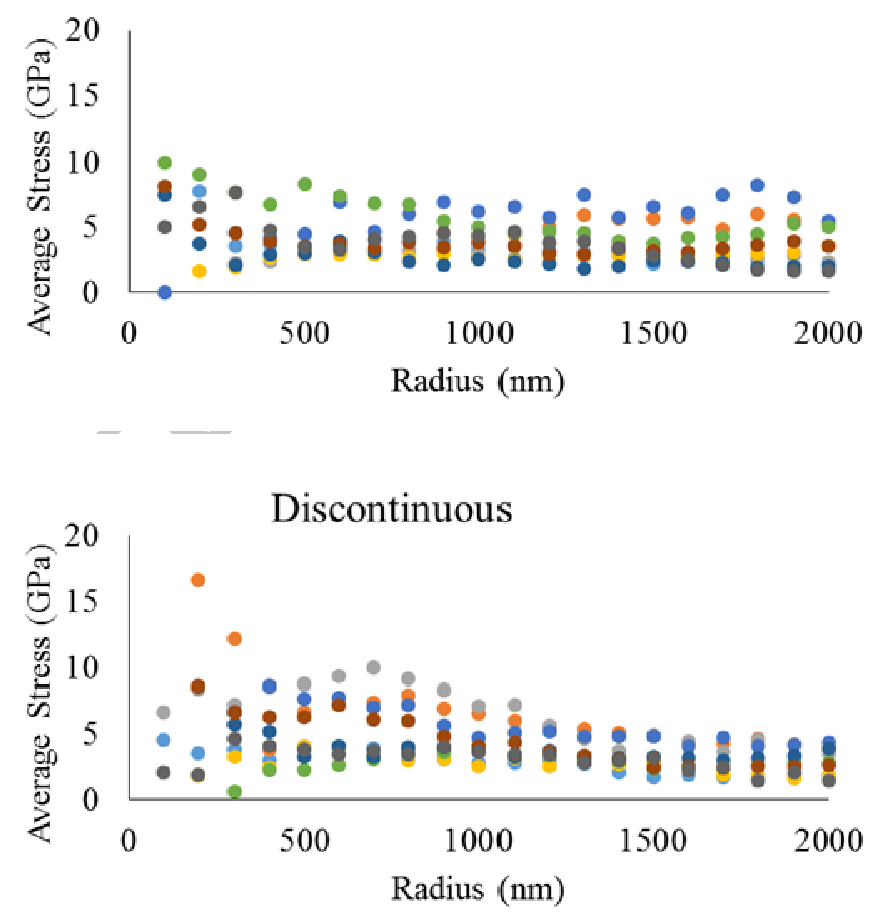

Figure 9. Results from 10 continuous, 9 disc. w/ GB slip, and 9 discontinuous DC-GB intersections. Average stress was determined at radii every $100 \mathrm{~nm}$ from the intersection points. Each color represents a different DC-GB intersection that was characterized with EBSD. 
The specimen strained in argon to $2.5 \%$ was then strained additional increments of $2 \%$ and $2.7 \%$ in simulated BWR NWC water to a total strain of $7.2 \%$. Crack initiation sites were characterized according to the DC-GB intersection type (as determined after the $2.5 \%$ straining in argon). Figure 10 shows example SEM images of (a) continuous, (b) disc. w/ GB slip and (c) discontinuous DC-GB intersections taken after the $2.5 \%$ argon strain increment (left) and after cracks initiated during the 7.2\% BWR NWC strain increment (right). This data, and a general characterization of DC-GB intersection densities performed after the $2.5 \%$ argon straining step, are shown in Table 3. All cracks characterized were initiation sites, and on the order of several microns.

Cracks also formed away from DC-GB intersections and at the intersection of three grains. Cracks that appeared to originate at these intersections where characterized as triple junction (TJ) cracks, regardless of whether the crack was also intersected by a dislocation channel. Of the $40 \mathrm{TJ}$ cracks that occurred after $4.5 \%$ total strain, $50 \%$ of them were noted to have also been intersected by a channel ( 5 continuous, 4 disc. w/ GB slip, and 11 discontinuous). However, since it is impossible to factor out the effects of the TJ from the channel, the TJ cracks were characterized separately from the cracks at DC-GB intersections. The importance of TJ in cracking will be examined later in the discussion section. The category "Unknown DC-DB intersection type" captures cracks that occurred at DC-GB intersections in which the dislocation channel formed after characterization (during straining in BWR-NWC). Cracks that occurred along grain boundaries at which there was no dislocation channel apparent in the SEM images were classified as "No visible DC". 

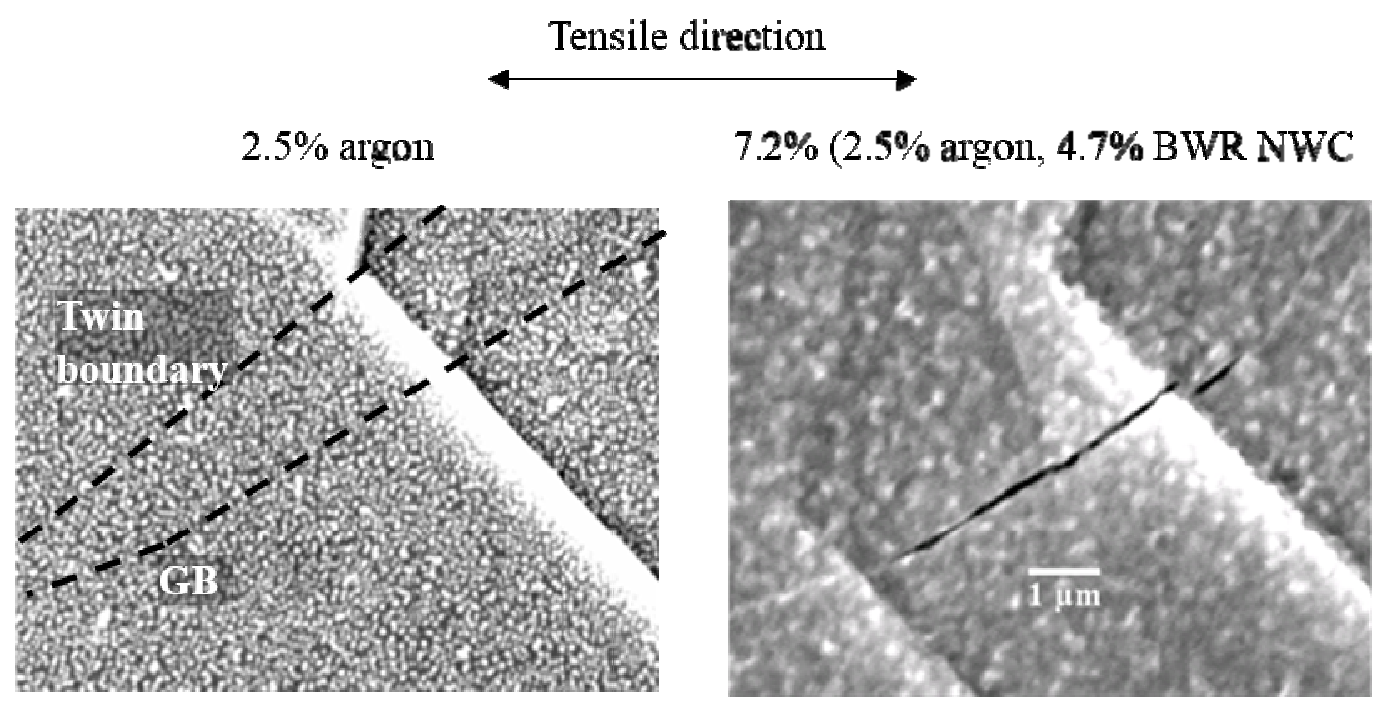

(a)
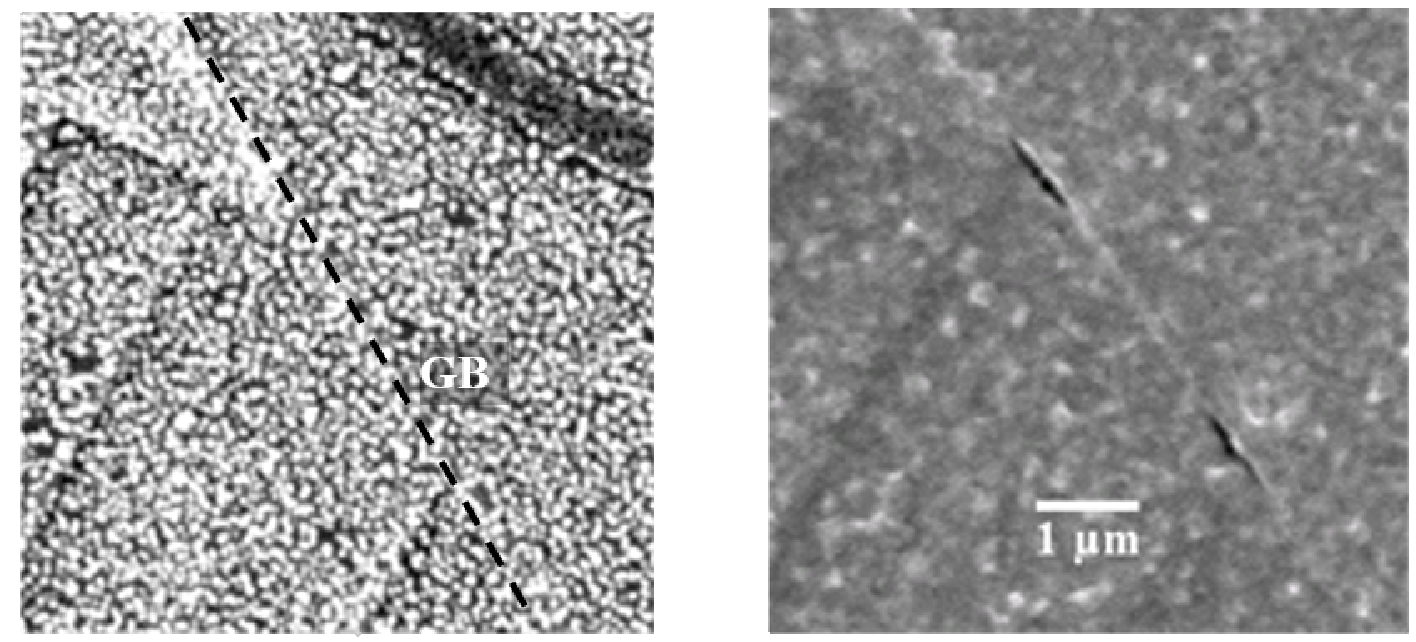

(b)
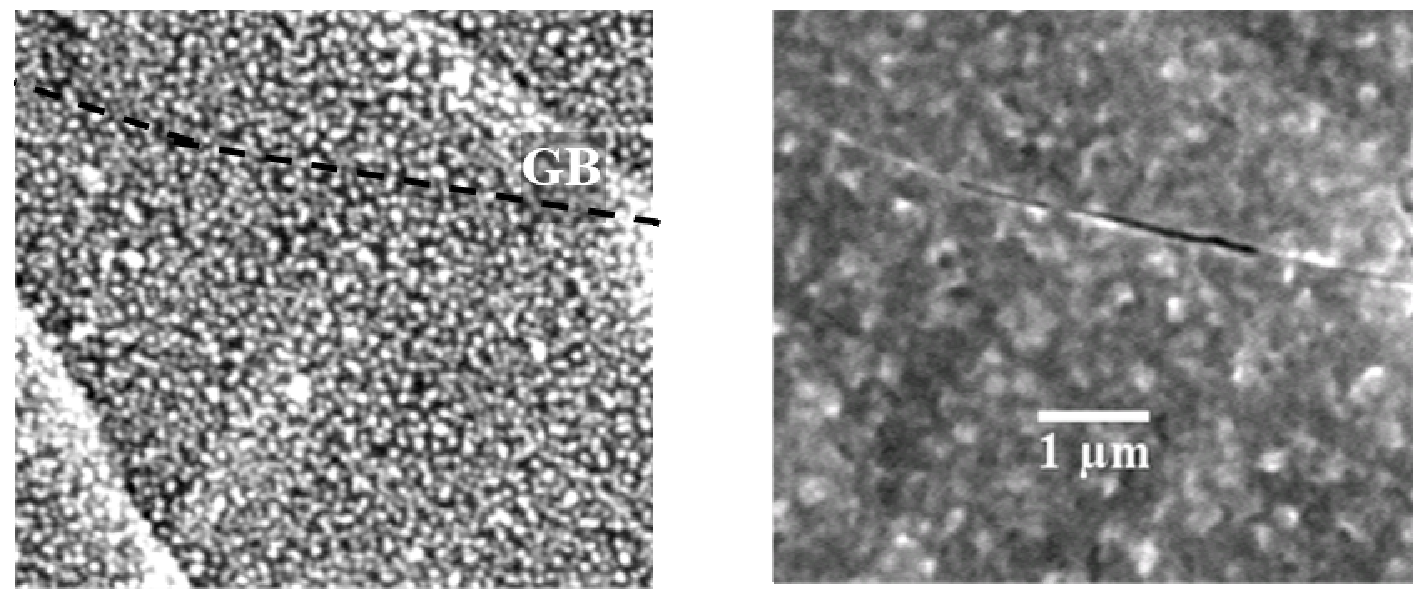

(c) 
Figure 10. Examples of (a) C, (b) D/GB and (c) D GB intersections that resulted in crack initiation. Post $2.5 \%$ argon strain is shown on left and same area after the $7.2 \%$ total strain $(2.5 \%$ argon and $4.7 \%$ BWR) is shown on the right.

Table 3. Characterization of cracking at DC-GB intersections. The first column of data shows the bulk DC-GB densities, as measured after the 2.5 argon straining step. The next two columns show the number of cracks that occurred at each of the different location classifications.

\begin{tabular}{|c|c|c|c|}
\hline Crack location & $\begin{array}{c}\text { Number of DC-GB } \\
\text { intersections/mm } \text { (\% of }^{2} \\
\text { total intersections) }\end{array}$ & $\begin{array}{c}\text { Number of cracks } \\
\text { after 4.5\% strain } \\
\text { (\% of total cracks) }\end{array}$ & $\begin{array}{c}\text { Number of cracks } \\
\text { after 7.2\% strain } \\
\text { (\% of total cracks) }\end{array}$ \\
\hline Continuous & $385(53)$ & $11(12)$ & $27(14)$ \\
\hline Disc. w/ GB slip & $192(27)$ & $8(9)$ & $14(7)$ \\
\hline Discontinuous & $147(20)$ & $14(16)$ & $27(14)$ \\
\hline $\begin{array}{c}\text { Unknown DC-GB } \\
\text { intersection type }\end{array}$ & - & $7(8)$ & $18(9)$ \\
\hline No visible DC & - & $9(10)$ & $28(15)$ \\
\hline TJ & - & $40(45)$ & $79(41)$ \\
\hline
\end{tabular}

\section{Discussion}

The results are analyzed with respect to the slip oxidation model for crack initiation, focusing on the potential roles of both strain and stress in crack initiation. That is, the question to be answered is whether local strains or local stresses are the key features responsible for initiation of IASCC cracks in the context of the slip oxidation model. The conclusions reached are compared with prior work and are shown to be supported by the work of others examining IASCC.

It is important to note that in all experiments in this study, cracking only occurred during the strain increments performed in the BWR NWC environment. No cracks were observed after the argon straining. This is an expected result as IASCC is a stress corrosion cracking process 
that occurs only in the presence of a corrosive environment. Without the aggressive environment, cracked oxide layers would repassivate before the cracks developed. According to the slip oxidation model, cracking of the passive oxide layer is a critical step in promoting IGSCC [26], [27]. Cracking occurs either by slip in grain boundaries below the oxide layer causing it to rupture, or by high local stress that overcomes the cohesive strength of the oxide layer at the grain boundary.

In particular, the values of the stress and strain at the DC-GB intersection are important as this is the location at which cracking preferentially occurs. Of the cracks that appeared at DCGB intersections, it is observed that the majority occurred at continuous and discontinuous DCGB intersections, in similar numbers. However, Table 3 also shows that the majority of channels that intersect a grain boundary will result in a continuous DC. Figure 11 shows the cracking fraction normalized to the total number of each type of DC-GB intersection that exists in the area characterized for cracking. The error bars were determined using Equation 3. It is clear that discontinuous DC-GB intersections are the most susceptible to cracking, with continuous and disc. w/ GB slip resulting in similar levels of cracking susceptibility. The high susceptibility to cracking exhibited by the discontinuous DC-GB intersections compared to disc. w/ GB slip shows that it is the local stress, not slip in the boundary, which controls cracking. 


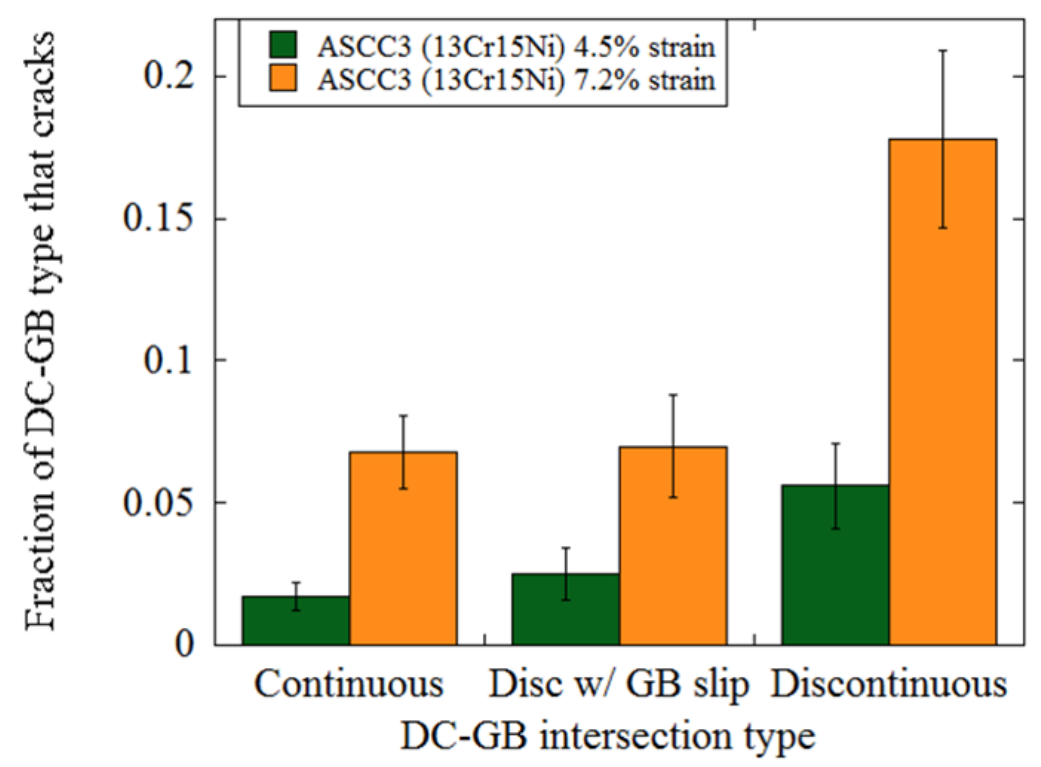

Figure 11. Fraction of DC-GBs were crack initiation was found. Fractions are estimated based on bulk DC-GB density measurements, found in Table 3. The error bars were calculated using Equation 3.

Previous work has showed that exposure to $288^{\circ} \mathrm{C}$ BWR NWC for five days (about the length of the SCC tests in this study) results in an oxide layer of $\sim 100 \mathrm{~nm}$ [28]. For most all boundaries that were characterized, the amount of grain boundary slip (Figure 5) exceeded the oxide thickness. The out-of-plane displacement is of particular interest since fresh metal is exposed if the displacement exceeds the oxide layer thickness. Figure 12 shows the out-of-plane portion of the displacement measurements vs. the total displacement (from Figure 5). The average out-of-plane displacement in the grain boundary was $104 \mathrm{~nm}$ and the largest was 618 $\mathrm{nm}$. This is sufficient to rupture the oxide layer and cause IASCC if slip in the grain boundary were controlling. However, cracks initiating at a DC-GB intersection are not directly correlated to the amount of slip within the channel. Recall from Table 2 and Figure 3 that discontinuous channels had the smallest displacement of the three types by about a factor of 3 . This means that 
IASCC crack initiation does not occur as a direct result of strain, either in the grain boundary or the dislocation channel. We next consider the role of stress caused by the dislocation channel intersection with the grain boundary.

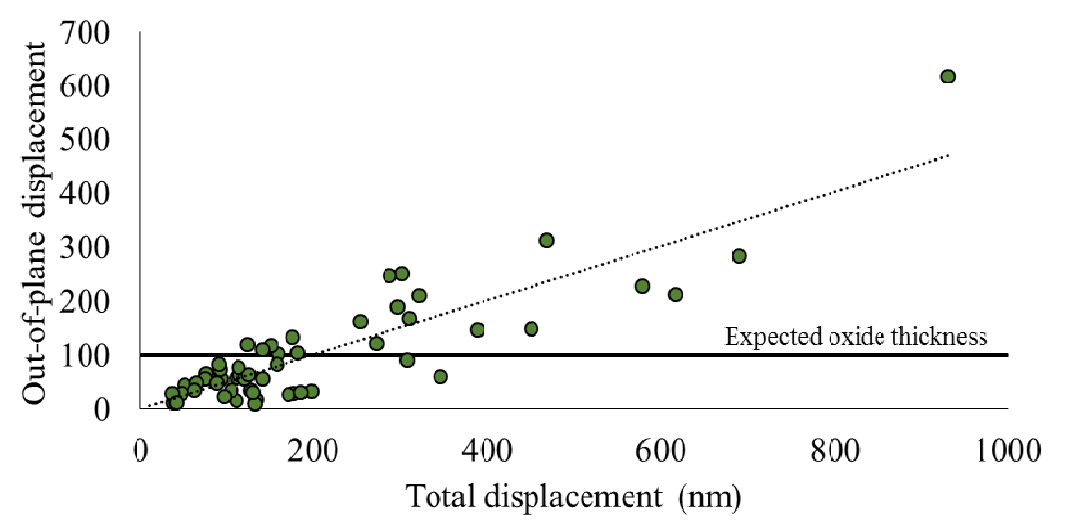

Figure 12. Out-of-plane portion of the grain boundary slip measurements vs total displacement (in-plane and out-of-plane). Like Figure 5, these measurements represent all of the displacement in the boundary, which in some cases was due to multiple dislocation channels contributing to the total slip. The trend line and the expected oxide thickness are marked on the graph.

Evidence of the importance of stress in IASCC has been noted in studies examining the character of the grain boundaries susceptible to cracking [8], [9], [17], [29]. Grain boundaries normal to the tensile axis and adjacent to low Schmid factor grains, where the resolved normal stress from the applied tensile stress is highest, were found to exhibit a high propensity for cracking. Had shear slip at the grain boundary been controlling the crack initiation, it is expected that the boundaries near $45^{\circ}$ to the tensile axis would have been more susceptible to cracking, as seen in Alexandreanu's studies on Ni-16Cr-9Fe in $360{ }^{\circ} \mathrm{C}$ primary water [30].

Strain in continuous channels is accommodated by either by the transfer of slip to the neighboring grain or by activating a dislocation source in the neighboring grain. In a similar 
manner, disc. w/ GB slip accommodate strain by inducing slip in the grain boundary. In the case of discontinuous channels, the dislocations pile-up at the grain boundary, causing an increase of stress locally. A discontinuous channel in a sample strained to $2.5 \%$ macroscopic strain may contain up to $\sim 200 \%$ strain within the channel, based on the displacement measurements shown in Figure 3, and assuming a channel width of $100 \mathrm{~nm}$. This is equivalent to almost 800 dislocations in a channel. In work by Evrard and Sauzay [15], similar channels (100 nm wide) were modeled using finite element analysis, as this was believed to describe the deformation over multiple parallel slip planes better than simple dislocation pile-up models which assume a single slip plane. It was found that the dislocation channels increased the stress by a factor of $\sim 4$ over the applied stress determined on the boundary.

High resolution EBSD was used to make direct measurements of the local elastic strain field, from which the local stress field was determined according Hooke's law. As shown in Figure 13, the ledges created by out-of-plane dislocation channel and grain boundary slip interfered with the pattern collection by blocking the path from the backscattered beam to the detector. This created significant difficulty in collecting the data in the region close to the DCGB intersection. As a result, no data was collected at less than $100 \mathrm{~nm}$ from the DC-GB intersection. It should also be noted that the values of the stress were higher than expected. This is believed to be due to surface damage caused during the irradiation and subsequent straining that distorted the crystal lattice near the surface and caused Kikuchi bands to be slightly blurred. As such, the value of these numbers is in the relative stress levels of the different types of DCGB intersections. The results do show that stress tends to be elevated at the GB, and that there are cases where stress at discontinuous DC-GB intersections reach higher levels (in one case, nearly double) than those observed at continuous or disc. w/ GB slip (Figure 8) intersections. 


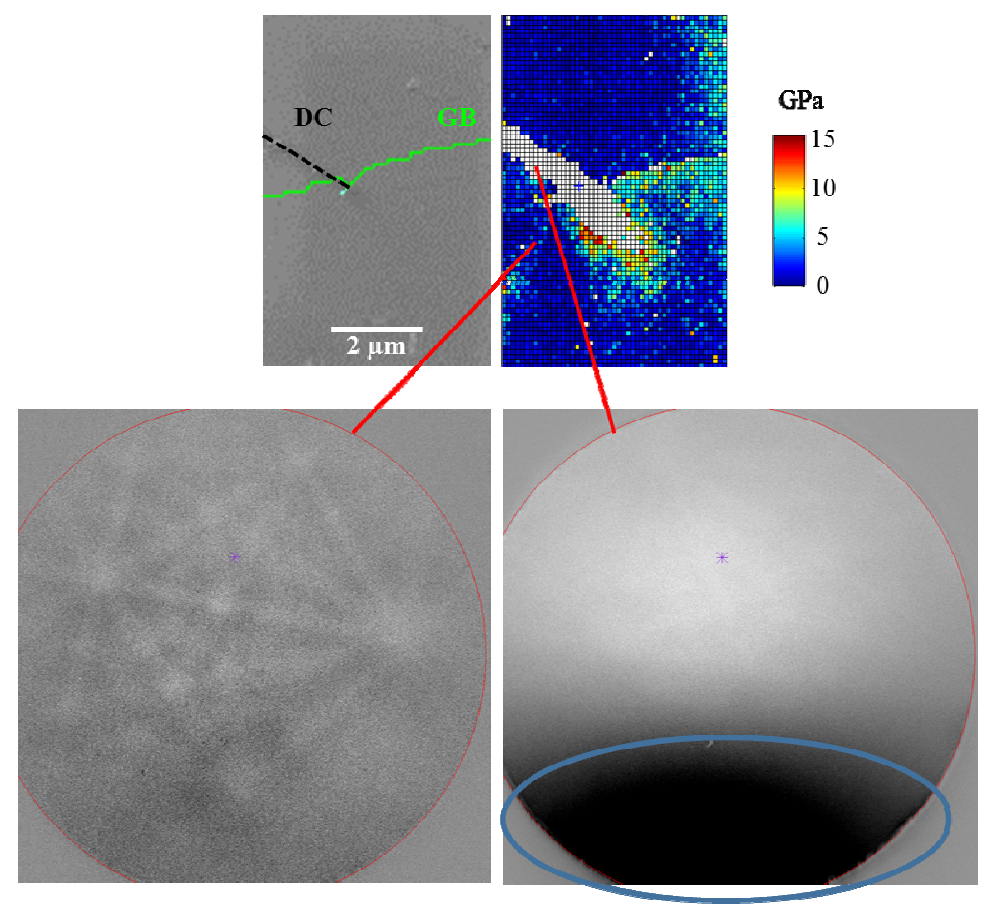

Figure 13. EBSD map of a discontinuous DC-GB intersection. The uncharacterized (white) area along the length of the channel was where the EBSD pattern was partially blocked by the emerging channel.

The observations of high stress due to discontinuous DC-GB intersections are supported by atomistic modeling that has examined the interactions of dislocations with grain boundaries [16], as well as in-situ TEM straining experiments [31]. Farkas et al. [17] modeled austenitic fcc metal using the Mishin nickel potential [32]. Polycrystalline digital samples were constructed, with a diameter of up to $50 \mathrm{~nm}$. The simulated grain structure was based on actual grain orientations from experimental samples, as determined using EBSD. Uniaxial strain-controlled virtual tensile tests at constant temperature were performed using on the large-scale atomic/molecular massively parallel simulator (LAMMPS) code [33] and the Virginia Tech supercomputer infrastructure, at a strain rate of $3 \times 10^{8} \mathrm{~s}^{-1}$. 
Dislocations were observed [16] to impinge on a boundary, and the buildup of stress in the boundary region was followed quantitatively. The stress increased locally to values as high as $9 \mathrm{GPa}$, decreasing when stress was relieved by the dislocations moving into the boundary and eventually transmitting across the boundary into the adjacent grain. Areas where dislocations were transmitted across the boundary generally exhibited lower stress levels than areas where transmission did not occur. Furthermore, if the dislocations were not transmitted into the neighboring grains, the high stresses typically resulted in crack initiation. This was particularly true near a TJ, which acted as stress concentrators and where a number of cracks were found to initiate.

These results show that despite large differences in the grain size and strain rate, stress localization in this type of microstructure can lead to crack initiation when dislocations are not transmitted across a grain boundary. The atomistic simulations also point out to the importance of triple junctions in crack initiation. Quantitative comparisons have not been attempted due to the above mentioned differences in length and time scales, but it is certainly possible that stress buildup at the boundaries and triple junctions plays a critical role across length and time scales.

Kamaya et al. [34], using finite element modeling, have also observed the high levels of stress at TJ, due to the deformation constraints caused by the adjacent grains. As the deformation constraints in an irradiated sample are significantly higher than that of unirradiated one, it is expected that the relative level of stress at the TJ will be even high in the irradiated steel. It is believed that the cracks that occurred at a TJ in the experiments (Table 3) were a result of this elevated stress, similar to cracks that form at discontinuous DC-GB intersections. The simulations clearly showed that un-accommodated and un-transmitted slip arriving at the boundary created very high local stresses. Even though the simulations were carried out at the 
extremely high strain rates necessitated by the molecular dynamics technique, the results of high stress buildup and subsequent crack initiation provide clear support for the idea that it is these areas of high stresses at discontinuous DC-GB intersections that result in crack initiation.

Additional confirmation on importance of stress at DC-GB intersections is provided by in-situ TEM straining experiments performed on austenitic stainless steel samples irradiated insitu at in the IVEM-Tandem microscope at Argonne National Laboratory [35], [36] at room temperature with $1 \mathrm{MeV} \mathrm{Kr}$ ions to a doses between 0.1-1 dpa [31], [37]. The in-situ straining revealed dislocation pile-ups in an irradiated 304 stainless steel [31]. When the pile-up could not be accommodated by slip transfer, stress was eventually relieved by crack nucleation. Similar to the atomistic model results, the TEM experiments performed by Cui et al. [37], revealed over 60 dislocations in a pile-up at the grain boundary before stress was relieved through slip transmission into the adjacent grain.

The in-situ TEM studies also provide a possible explanation for the cracking at a TJ. Cui et al. [37] reported that dislocations within a channel, once incorporated in the grain boundary, caused dislocation emission from the vicinity of a triple junction. If dislocation propagation away from the sources in the vicinity of the TJ was prohibited by the presence of the irradiation defects, the response may be for the triple junction to crack.

The final categories of cracks to address are those that formed where no channels intersections were previously observed. As noted earlier, straining in BWR NWC resulted in the creation of additional channels, an example of which is shown in Figure 10a, where a dislocation channel is observed on the left side of the SEM image only after straining in BWR NWC to 7.2\%. Thus, they can only be characterized as either continuous or discontinuous. Figure 14 shows the characterization of the slip (continuous or discontinuous) for the 25 cracks in the 
"Unknown DC-GB intersection type" category. As expected, and consistent with results in Figure 11, cracking propensity at discontinuous (discontinuous or disc. w/ GB slip) boundaries was statistically higher than at continuous boundaries.

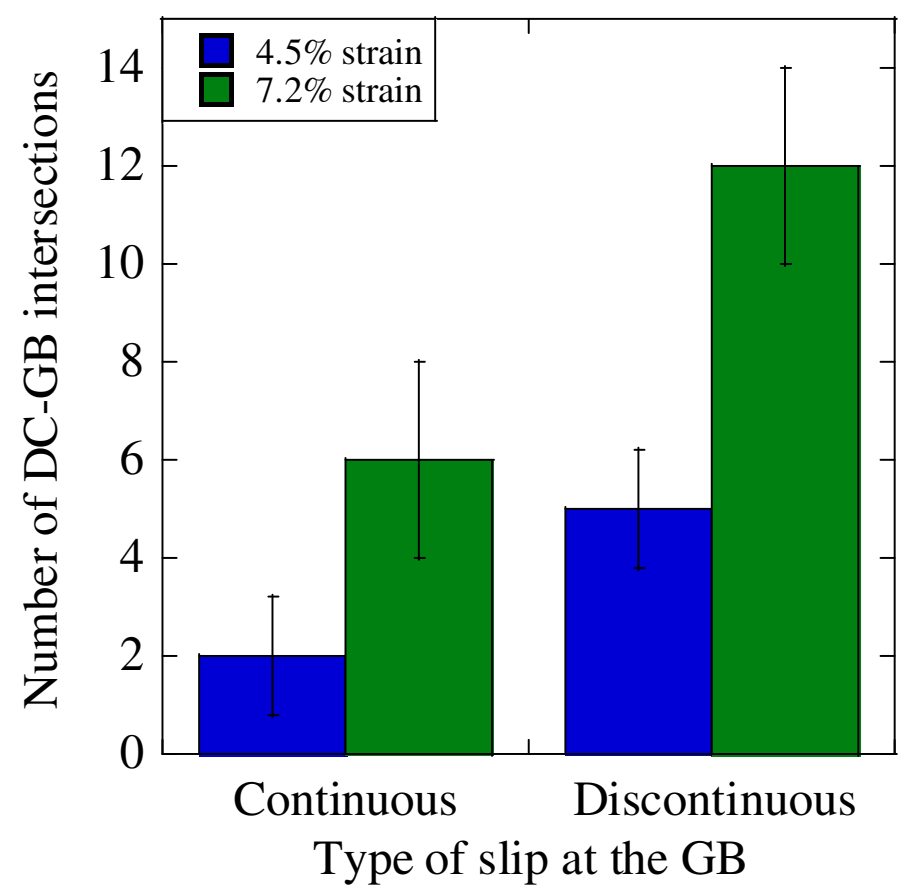

Figure 14. Number of crack DC-GB intersection in the classification "Unknown DC-GB intersection type" which are continuous, or discontinuous, based on SEM observations.

While the data solidly supports localized stress at discontinuous dislocation channel-grain boundary intersections as the key factor in IASCC, it may be noted that only $18 \%$ of the most susceptible locations (discontinuous DC-GB intersections) crack. If a threshold in stress is required for cracking, then not all boundaries or DC-GB intersections will experience the same local stress for a given applied stress. Obtaining a quantitative measure of the local stress will be required to determine the value of this threshold stress. Further, variability in local grain boundary structure or chemistry may also exert an influence on the cracking propensity. Thus, full understanding of the conditions for IASCC requires a quantitative characterization of the 
local stress state and the influence of other factors. These results also examine only crack initiation, and additional work is needed to understand and characterize the crack propagation. At that point, the tools will be in place to develop predictive capabilities as well as mitigation strategies.

\section{Conclusions}

Partitioning localized deformation into three fundamental modes, based on how the channels interact with the grain boundary, revealed that high local stress occurring as a result of dislocation pile-ups in discontinuous dislocation channels at the intersection with grain boundaries is the likely cause of IASCC in irradiated steel. It is the inability of these channels to relieve stress by either slip in the adjacent grain or in the grain boundary, which results in high local stresses and an increased susceptibility to IGSCC initiation. Where more slip has occurred in a discontinuous channel, a larger number of dislocations will pile up, exerting higher stress on the grain boundary. Channels that induce slip across or within a grain boundary relieve the local stresses and thus, show less susceptibility to cracking. The observation that discontinuous channel-grain boundary intersections are locations of high stress is supported by both in-situ straining of irradiated steels in the TEM and atomistic simulation of dislocation-grain boundary interaction in which channels that were unable to transfer strain underwent cracking.

\section{Acknowledgements}

The authors acknowledge Alexander Flick for his assistance conducting the constant extension rate tensile tests in the Irradiated Materials Testing Laboratory at the University of Michigan, as well as the staff of the Michigan Ion Beam Laboratory, Ovidiu Toader and Fabian Naab for their assistance in performing the proton irradiations. The electron microscopy was 
accomplished at the Electron Microscopy Center at Argonne National Laboratory (a U.S.

Department of Energy Office of Science Laboratory operated under Contract No. DE-AC02-

06CH11357 by U Chicago Argonne, LLC). The NSF IRD program is also acknowledged for support. The authors acknowledge Advanced Research Computing at Virginia Tech for providing computational resources and technical support that have contributed to the results reported within this paper. URL: http://www.arc.vt.edu. Research supported by the U.S. Department of Energy, Office of Basic Energy Sciences, Division of Materials Sciences and Engineering under Award DE-FG02-08ER46525 (McMurtrey, Was, Robertson, Cui: experimental studies and Smith: computational studies) and the NSF IRD program (Farkas: computational studies).

\section{References}

[1] S. J. Zinkle and G. S. Was, "Materials challenges in nuclear energy," Acta Mater., vol. 61, no. 3, pp. 735-758, Feb. 2013.

[2] K. Fukuya, "Current understanding of radiation-induced degradation in light water reactor structural materials," J. Nucl. Sci. Technol., vol. 50, no. 3, pp. 213-254, 2013.

[3] P. Scott, "Review article A review of irradiation assisted stress corrosion cracking," $J$. Nucl. Mater., vol. 211, pp. 101-122, 1994.

[4] J. T. Busby, G. S. Was, and E. A. Kenik, "Isolating the effect of radiation-induced segregation in irradiation-assisted stress corrosion cracking of austenitic stainless steels," J. Nucl. Mater., vol. 302, no. 1, pp. 20-40, 2002.

[5] K. Fukuya, M. Nakano, K. Fujii, and T. Torimaru, "Role of radiation-induced grain boundary segregation in irradiation assisted stress corrosion cracking," J. Nucl. Sci. Technol., vol. 41, no. 5, pp. 594-600, 2004.

[6] Z. Jiao and G. S. Was, "Impact of localized deformation on IASCC in austenitic stainless steels," J. Nucl. Mater., vol. 408, no. 3, pp. 246-256, 2011.

[7] T. Onchi, K. Dohi, N. Soneda, M. Navas, and M. L. Castano, "Mechanism of irradiation assisted stress corrosion crack initiation in thermally sensitized 304 stainless steel," $J$. Nucl. Mater., vol. 340, no. 2-3, pp. 219-236, 2005. 
[8] E. A. West, M. D. McMurtrey, Z. Jiao, and G. S. Was, "Role of Localized Deformation in Irradiation-Assisted Stress Corrosion Cracking Initiation," Metall. Mater. Trans. A, vol. 43, no. 1, pp. 136-146, Jul. 2011.

[9] M. Le Millier, O. Calonne, J. Crépin, and C. Duhamel, "Irradiation assisted stress corrosion cracking of stainless steels in a PWR environment ( A combined approach )," Proc. fifteenth Int. Conf. Environ. Degrad. Mater. Nucl. power Syst. water React., pp. 1293-1307, 2011.

[10] J. Sharp, "Deformation of neutron irradiated copper alloys," Acta Metall., vol. 22, no. 4, pp. 449-457, 1974.

[11] D. J. Edwards, B. N. Singh, and J. B. Bilde-Sørensen, "Initiation and propagation of cleared channels in neutron-irradiated pure copper and a precipitation hardened $\mathrm{CuCrZr}$ alloy," J. Nucl. Mater., vol. 342, no. 1-3, pp. 164-178, 2005.

[12] S. Nogami, Y. Sato, and A. Hasegawa, "Fatigue Crack Initiation in Proton-Irradiated Austenitic Stainless Steel," J. Nucl. Sci. Technol., vol. 48, no. March 2015, pp. 12651271, 2011.

[13] R. P. Tucker, "Dislocation Channeling in Neutron-Irradiated Niobium," J. Appl. Phys., vol. 40, no. 1, p. 400, 1969.

[14] M. Sauzay, K. Bavard, and W. Karlsen, “TEM observations and finite element modelling of channel deformation in pre-irradiated austenitic stainless steels - Interactions with free surfaces and grain boundaries," J. Nucl. Mater., vol. 406, no. 1, pp. 152-165, 2010.

[15] P. Evrard and M. Sauzay, "Modelling of the effect of dislocation channel on intergranular microcrack nucleation in pre-irradiated austenitic stainless steels during low strain rate tensile loading," J. Nucl. Mater., vol. 405, no. 2, pp. 83-94, 2010.

[16] M. McMurtrey, G. Was, B. Cui, I. Robertson, L. Smith, and D. Farkas, "Strain Localization at Dislocation Channel-Grain Boundary Intersections in Irradiated Stainless Steel," Int. J. Plast., vol. 56, pp. 219-231, 2014.

[17] M. D. McMurtrey, G. S. Was, L. Patrick, and D. Farkas, "Relationship between localized strain and irradiation assisted stress corrosion cracking in an austenitic alloy," Mater. Sci. Eng. A, vol. 528, no. 10-11, pp. 3730-3740, 2011.

[18] M. D. Mcmurtrey and G. S. Was, "Role of slip behavior in the irradiation assisted stress corrosion cracking in austenitic steels," Proc. fifteenth Int. Conf. Environ. Degrad. Mater. Nucl. power Syst. water React., pp. 1383-1394, 2011.

[19] G. S. Was, B. Alexandreanu, and J. Busby, "Localized deformation induced IGSCC and IASCC of austenitic alloys in high temperature water," Adv. Fract. Fail. Prev. Pts 12 , vol. 261-263, pp. 885-901, 2004. 
[20] E. A. West and G. S. Was, "A model for the normal stress dependence of intergranular cracking of irradiated 316L stainless steel in supercritical water," J. Nucl. Mater., vol. 408, no. 2, pp. 142-152, 2011.

[21] R. E. Stoller, M. B. Toloczko, G. S. Was, a. G. Certain, S. Dwaraknath, and F. a. Garner, "On the use of SRIM for computing radiation damage exposure," Nucl. Instruments Methods Phys. Res. Sect. B Beam Interact. with Mater. Atoms, vol. 310, pp. 75-80, Sep. 2013.

[22] G. Frens, "Controlled Nucleation for the Regulation of the Particle Size in Monodisperse Gold Suspension,” Nat. Phys. Sci., vol. 241, pp. 20-22, 1973.

[23] K. C. Grabar, R. G. Freeman, M. B. Hommer, and M. J. Natan, "Preparation and Characterization Monolayers," vol. 67, no. 4, pp. 1217-1225, 1995.

[24] A. D. Kammers and S. Daly, "Self-Assembled Nanoparticle Surface Patterning for Improved Digital Image Correlation in a Scanning Electron Microscope," Exp. Mech., vol. 53, no. 8, pp. 1333-1341, Mar. 2013.

[25] A. J. Wilkinson, G. Meaden, and D. J. Dingley, "High-resolution elastic strain measurement from electron backscatter diffraction patterns: new levels of sensitivity.," Ultramicroscopy, vol. 106, no. 4-5, pp. 307-313, 2006.

[26] P. L. Andresen and F. P. Ford, "Fundamental modeling of environmental cracking for improved design and lifetime evaluation in BWRs," Int. J. Press. Vessel. Pip., vol. 59, no. 1-3, pp. 61-70, Jan. 1994.

[27] P. L. Andresen and F. P. Ford, "Life Prediction by Mechanistic Modeling and System Monitoring of Environmental Cracking of Iron and Nickel Alloys in Aqueous Systems*," Mater. Sci. Eng. A, vol. 103, pp. 167-184, 1988.

[28] Z. Jiao, "Personal communication." p. Personal communication, 2014.

[29] E. A. West and G. S. Was, "A Model for the Normal Stress Dependence of Intergranular Fracture of Irradiated 316L Stainless Steel,” J. Nucl. Mater., vol. 408, pp. 142-152, 2011.

[30] B. Alexandreanu, "PhD Thesis," University of Michigan: Ann Arbor, 2002.

[31] B. Cui, J. Kacher, M. McMurtrey, G. Was, and I. Robertson, "The influence of irradiation damage on slip transfer across grain boundaries," Acta Mater., vol. 65, pp. 150-160, 2014.

[32] Y. Mishin, D. Farkas, and M. Mehl, "Interatomic potentials for monoatomic metals from experimental data and ab initio calculations," Phys. Rev. B, vol. 59, no. 5, pp. 3393-3407, 1999. 
[33] S. Plimpton, "Fast Parallel Algorithms for Short Range Molecular Dynamics.pdf," J. Comput. Phys., vol. 117, pp. 1-19, 1995.

[34] M. Kamaya, Y. Kawamura, and T. Kitamura, "Three-dimensional local stress analysis on grain boundaries in polycrystalline material," Int. J. Solids Struct., vol. 44, no. 10, pp. 3267-3277, May 2007.

[35] M. Briceño, J. Fenske, M. Dadfarnia, P. Sofronis, and I. M. Robertson, "Effect of ion irradiation-produced defects on the mobility of dislocations in 304 stainless steel," J. Nucl. Mater., vol. 409, no. 1, pp. 18-26, Feb. 2011.

[36] J. Kacher, G. S. Liu, and I. M. Robertson, "In situ and tomographic observations of defect free channel formation in ion irradiated stainless steels.," Micron, vol. 43, pp. 1099-1107, 2012.

[37] B. Cui, M. D. McMurtrey, G. S. Was, and I. Robertson, "Micromechanistic origin of irradiation-assisted stress corrosion cracking," Philos. Mag., vol. Submitted, 2014. 